\title{
Estudio del efecto citotóxico e irritativo de jabones para la limpieza cutánea
}

\author{
Juan P. Castanedo-Cázares, Juan D. Cortés-García, Mayra F. Cornejo-Guerrero, Bertha Torres-Álvarez \\ y Diana Hernández-Blanco* \\ Universidad Autónoma de San Luis Potosí, Hospital Central "Dr. Ignacio Morones Prieto", Departamento de Dermatología, San Luis Potosí, México
}

\section{Resumen}

Introducción: El jabón para el aseo cutáneo es de empleo común entre la población, sin embargo, es posible que cause daño a las células de la piel y modifique la barrera cutánea. Objetivo: Determinar el efecto citotóxico de los jabones en queratinocitos cultivados in vitro y correlacionarlo con la irritación clínica. Método: Se realizó una encuesta para conocer los jabones comerciales más utilizados y su cantidad; posteriormente, se evaluó su citotoxicidad en cultivos de queratinocitos humanos mediante el método de resazurina. Los jabones con mayor y menor citotoxicidad se aplicaron en piel de voluntarios sanos para evaluar su efecto en la barrera cutánea mediante ensayos de colorimetría y pérdida transepidérmica de agua. Resultados: De los jabones analizados, 37 \% demostró ser tóxico para los queratinocitos in vitro. El jabón con mayor toxicidad indujo el mayor índice de eritema y pérdida transepidérmica de agua, en comparación con el jabón menos tóxico y el vehículo empleado como solución control. Conclusión: Los jabones comercializados para el aseo cutáneo pueden incluir ingredientes químicos que dañan los queratinocitos humanos y causan irritación subclínica de la barrera cutánea. Su utilización puede agravar dermatosis preexistentes, generar dermatitis xerósica o de contacto irritativa y causar atrofia y dermatoporosis.

PALABRAS CLAVE: Citotoxicidad. Jabón. Eritema. Pérdida de agua transepidérmica.

\section{Study of the cytotoxic and irritant effects of skin cleansing soaps}

\begin{abstract}
Introduction: The use of soap for skin cleansing is common among the population. However, it is possible that it causes damage to skin cells and disrupts the skin barrier. Objective: To determine the cytotoxic effect of soaps on in vitro-cultured keratinocytes and to correlate it with clinical irritation. Method: A survey was conducted to find out the most widely used commercial soaps and their number. Subsequently, their cytotoxicity was evaluated in human keratinocyte cultures using the resazurin assay. The soaps with the highest and lowest cytotoxicity were applied to the skin of healthy volunteers to assess their effect on the skin barrier using colorimetry and transepidermal water loss (TEWL) assays. Results: Of the analyzed soaps, $37 \%$ were shown to be toxic to keratinocytes in vitro. The soap with the highest toxicity induced the highest rate of erythema and TEWL, in comparison with the least toxic soap and the vehicle used as the control solution. Conclusion: Soaps marketed for skin cleansing can contain chemical ingredients that damage human keratinocytes and cause skin barrier subclinical irritation. Their use can worsen preexisting dermatoses, generate xerotic or irritant contact dermatitis, and cause atrophy and dermatoporosis.
\end{abstract}

KEY WORDS: Cytotoxicity. Soap. Erythema. Transepidermal water loss.

Correspondencia:

*Diana Hernández-Blanco

E-mail: dvianey55@hotmail.com
Fecha de recepción: 10-06-2019

Fecha de aceptación: 13-04-2020

DOI: $10.24875 / G M M .20005332$
Gac Med Mex. 2020;156:426-431

Disponible en PubMed

www.gacetamedicademexico.com

0016-3813/@ 2020 Academia Nacional de Medicina de México, A.C. Publicado por Permanyer. Este es un artículo open access bajo la licencia CC BY-NC-ND (http://creativecommons.org/licenses/by-nc-nd/4.0/). 


\section{Introducción}

El jabón para el aseo cutáneo es de uso común en nuestra sociedad. Este producto constituye una mezcla de sales de ácidos grasos con la capacidad de formar micelios al combinarse con sustancias lipofílicas en un medio acuoso. ${ }^{1}$ Debido a esta propiedad química, sustrae el contenido lipídico del estrato córneo y favorece su disolución. ${ }^{2}$ La remoción superficial de esta capa implica la eliminación de contaminantes exógenos, reducción de olores y la modificación de la microbiota cutánea; ${ }^{3}$ sin embargo, el uso excesivo o repetido de jabón puede dañar la barrera cutánea, con la consecuente exposición de los queratinocitos epidérmicos a los componentes químicos del producto. El pH fisiológico del estrato córneo oscila entre 4.5 y 5, pero el jabón puede alcalinizarlo. ${ }^{4}$ La disrupción de la estructura lipídica de la piel provoca irritación, estrés oxidativo e inflamación; ${ }^{5}$ las manifestaciones clínicas consisten en dermatitis por contacto acompañada por enrojecimiento, descamación, prurito y exudado. En condiciones experimentales es posible detectar inflamación subclínica en el lapso de cuatro horas después de que el jabón está en contacto con la superficie cutánea. ${ }^{6}$

Además de la naturaleza irritante del jabón, los surfactantes derivados son tóxicos para los queratinocitos. $^{7}$ La citotoxicidad se define como cualquier alteración de las funciones celulares básicas originada por el contacto con algún compuesto químico. ${ }^{8}$ La irritación cutánea debida al jabón se evalúa mediante ensayos in vivo que evalúan parámetros clínicos y fisiológicos, como el aumento del flujo sanguíneo $^{6}$ y la evaporación epidérmica de agua. ${ }^{9} \mathrm{El}$ efecto citotóxico se cuantifica en cultivos de queratinocitos mediante ensayos de daño, muerte, proliferación o modificación del metabolismo celular. ${ }^{8}$

En la práctica clínica es común observar efectos adversos debido a la utilización excesiva y continua de jabones para el aseo cutáneo, por lo general en niños y adultos de edad avanzada, así como en individuos con diversas dermatosis inflamatorias.

Se desconoce si el efecto citotóxico de los ingredientes químicos de los jabones comercializados en México participa en las manifestaciones relacionadas con la afectación del estrato córneo, por lo tanto, el objetivo de este trabajo fue determinar el efecto irritativo y citotóxico de una muestra de jabones disponibles en el mercado mexicano y analizar su posible relación.

\section{Método}

De abril a agosto de 2017 se interrogó a 300 asistentes consecutivos al Departamento de Dermatología del Hospital Central "Dr. Ignacio Morones Prieto", en San Luis Potosí, acerca del uso de jabón para aseo personal. Con base en la información proporcionada se seleccionaron los ocho productos comerciales más utilizados por los asistentes, así como por 30 voluntarios sanos que aceptaron participar previa firma de consentimiento informado. Se incluyeron personas con edad $>30$ años sin enfermedades cutáneas, mentales o sistémicas. El estudio fue aprobado por el comité de ética del hospital con el registro 2217

\section{Estudio de citotoxicidad}

- Cultivo celular. Se cultivaron queratinocitos humanos (células $\mathrm{HaCaT}$ ) en placas de cultivo de $25 \mathrm{~cm}^{2}$, en medio RPMI-1640 suplementado con $10 \%$ de suero bovino fetal, penicilina $(1000 \mathrm{UI} / \mathrm{mL})$ y estreptomicina $(10 \mathrm{mg} / \mathrm{mL})$; la incubación se llevó a cabo a $37{ }^{\circ} \mathrm{C}$ con $5 \%$ de $\mathrm{CO}_{2}$. Se realizaron subcultivos al lograr una confluencia de $80 \%$. Las células se cosecharon con tripsina/EDTA (0.1\%) durante 10 minutos, se resuspendieron en medio RPMI-1640 y se centrifugaron a 1500 rpm durante cinco minutos. Los subcultivos consecutivos se dividieron a razón de 1:3.

- Elaboración de la emulsión. Una vez obtenido el cultivo celular, se expuso a emulsiones de los jabones seleccionados, cuya cantidad se determinó mediante la estimación del uso real, para lo cual se midió la diferencia del peso en seco de la barra de jabón antes y después del lavado de manos. Se prepararon emulsiones de $2 \mathrm{mg} / \mathrm{mL}$ de las muestras de jabones en solución salina fisiológica, las cuales fueron identificadas con un código (uno al ocho); el pH se midió con un potenciómetro Thermo Electron Orion 410A ${ }^{\oplus}$ (Cole-Parmer, IL, Estados Unos). Los ensayos se realizaron de forma cegada.

- Ensayo de viabilidad. La viabilidad de las células se cuantificó mediante el ensayo de resarzurina. Después de cosechadas, $3 \times 10^{4}$ células se transfirieron a placas de 96 pozos y se cultivaron durante 24 horas. Posteriormente se removió el medio para añadir cada solución de jabón por 10 minutos y las células se lavaron con solución salina tamponada con fosfato. Finalmente, las células fueron cultivadas en medio RPMI con $20 \mu \mathrm{g} / \mathrm{mL}$ de resarzurina durante 
Tabla 1. Constituyentes químicos de los productos evaluados para el aseo cutáneo

\begin{tabular}{|c|c|c|}
\hline Producto (fabricante) & pH & Formulación \\
\hline 1. Zest ${ }^{\circledast}$ (Unilever) & 9.8 & $\begin{array}{l}\text { Oleato/palmitato/laurato de sodio, almidón de maíz, agua, glicerina, perfume, ácido láurico, cloruro de } \\
\text { sodio, citrato de sodio, ácido cítrico, EDTA, etidronato tetrasódico, PEG-45M, sílica, agua de } \\
\text { Cocos nucifera, extracto de fruta de Litchi chinencis, hidantoína DMDM, geraniol. }\end{array}$ \\
\hline $\begin{array}{l}\text { 2. Neutro Balance }{ }^{\circledR} \\
\text { (Colgate) }\end{array}$ & 9.7 & $\begin{array}{l}\text { Oleato/palmitato/laurato de sodio, glicerina, agua, dodecilbencensulfonato de sodio, cocamida MEA, fragancia, } \\
\text { cocamidopropil betaína, dióxido de titanio (CI77891), tetra-di-t-butil hidroxihidrocinamato, pentetato pentasódico. }\end{array}$ \\
\hline 3. Dove $®$ (Unilever) & 7.4 & $\begin{array}{l}\text { Lauroil de sodio, isetionato, ácido esteárico, palmitato de sodio, ácido láurico, agua, isetionato de sodio, } \\
\text { estearato de sodio, cocamidopropil betaína, kernelato de palma sódico, glicerina, perfume, cloruro de } \\
\text { sodio, óxido de cinc, EDTA, etidronato tetrasódico, alúmina, alfa-isometil ionone, alcohol bencílico, butilfenil } \\
\text { metilpropional, citronelol, cumarina, hexil cinámico, limoneno, linalol. }\end{array}$ \\
\hline $\begin{array}{l}\text { 4. Lipikar }{ }^{\circledast}(\text { La Roche } \\
\text { Posay) }\end{array}$ & 9.6 & $\begin{array}{l}\text { Palmato de sodio, estearato de sodio, cocoato sódico, agua, glicerina, dióxido de titanio (Cl77891), EDTA, } \\
\text { ácido etidrónico, ácido salićlico, cloruro de sodio, cinc PCA (C36985/1). }\end{array}$ \\
\hline 5. Cleanance ${ }^{\circledast}$ (Avene) & 6.8 & $\begin{array}{l}\text { Lauril sulfosucinato de sodio, maltodextrina, cocoil isetionato de sodio, ácido esteárico, agua, alcohol } \\
\text { cetearilo, parafina, agua termal, manteca de karité, ceteareth-6, aceite de Prunus amygdalus dulcis, ácido } \\
\text { cítrico, cera microcristalina, polietileno, serina, dióxido de titanio (CI77891). }\end{array}$ \\
\hline $\begin{array}{l}\text { 6. Kleenex } \\
\text { (Kimberly-Clark) }\end{array}$ & 10.3 & $\begin{array}{l}\text { Sebato de sodio, cocoato de sodio, agua, glicerina, aceite mineral, fragancia, cloruro de sodio, bióxido de } \\
\text { titanio, hidróxido de sodio, EDTA, ácido etidrónico, sílice amorfa, hidróxido de aluminio, aroma de crema de } \\
\text { coco y almendras }\end{array}$ \\
\hline $\begin{array}{l}\text { 7. Escudo }{ }^{\circledR} \\
\text { (Kimberly-Clark) }\end{array}$ & 10.0 & $\begin{array}{l}\text { Oleato de sodio, palmitato de sodio, agua, estearato de sodio, glicerina, laureato de sodio, miristato de sodio, } \\
\text { linoleato de sodio, palmitoleato de sodio, fragancia, cloruro de sodio, bióxido de titanio (Cl77891), pirtiona de } \\
\text { cinc, hidróxido de sodio, EDTA, ácido etidrónico, oxido de aluminio, verde } 3 \text { (Cl42053), rojo } 33 \text { (Cl17200). }\end{array}$ \\
\hline 8. Camay ${ }^{\circledast}$ (Unilever) & 9.7 & $\begin{array}{l}\text { Oleato/palmitato/laurato de sodio, almidón de maíz, agua, glicerina, perfume, ácido láurico, cloruro de } \\
\text { sodio, citrato de sodio, ácido cítrico, dióxido de titanio, PEG-45M, sílica, seda hidrolizada, extracto de flores } \\
\text { de rosa, extracto de flores de Jasminum officinale, aceite de Prunus amygdalus dulcis, aceite de flores } \\
\text { de Nelumbium speciosum, aceite de hojas de Mentha arvensis, aceite de Cymbopogon Martini, EDTA, } \\
\text { etidronato tetrasódico, hidantoína DMDM, hexil cinámico, alcohol bencílico, salicilato de bencilo, citronelol, } \\
\text { eugeniol, hidroxicitronelal, limoneno, linalol, Cl } 14700 .\end{array}$ \\
\hline
\end{tabular}

dos horas. Se cuantificó la fluorescencia con un espectrofluorómetro a $530 \mathrm{~nm}$ de excitación/590 nm de emisión. Los controles negativos fueron el medio de cultivo y se empleó solución salina como vehículo. Como control positivo se utilizó $0.3 \%$ de agua.

\section{Estudio clínico de irritación}

Se utilizaron las soluciones jabonosas con mayor y menor viabilidad in vitro, así como un placebo (solución fisiológica), que se aplicaron en la porción volar del antebrazo izquierdo utilizando cámaras de Finn. La evaluación cutánea se llevó a cabo antes de su colocación y después de 10, 30 y 60 minutos.

La irritación se cuantificó mediante la pérdida transepidérmica de agua en $\mathrm{g} / \mathrm{cm}^{2}$ y el eritema, mediante el eje $a^{*}$ del espacio de color CIELAB, con valores posibles de 0 a 50 . Los equipos utilizados fueron un evaporímetro (Dermalab ${ }^{\circledR}$, Cortex, Dinamarca) y un colorímetro de reflectancia difusa (CR-400 ${ }^{\circledR}$, Minolta, Japón). Las mediciones fueron obtenidas en instalaciones a temperatura controlada de $21^{\circ} \mathrm{C}$ y humedad relativa de $70 \%$.

\section{Análisis estadístico}

Se calculó una muestra de 30 personas para detectar una diferencia de 0.2 en la pérdida transepidérmica de agua entre la emulsión de jabón y el control negativo, asumiendo una desviación de 20, un intervalo de confianza de $95 \%$ a dos colas, $\alpha$ de 0.05 y poder de 0.8. Para los análisis descriptivos se usaron medidas de tendencia central. Las diferencias entre los grupos fueron analizadas mediante Anova y prueba de KruskalWallis, así como con análisis post hoc mediante prueba de Dunn. Se utilizó el programa Prisma GraphPad ${ }^{\circledR}$ versión 5.0 (San Diego, CA, Estados Unidos). Se consideró significativo un valor de $p<0.05$.

\section{Resultados}

El pH y los ingredientes de los jabones más utilizados por la población encuestada se incluyen en la Tabla 1. En el estudio clínico participaron 30 personas con edad promedio de 41 años, con rango de 30 a 


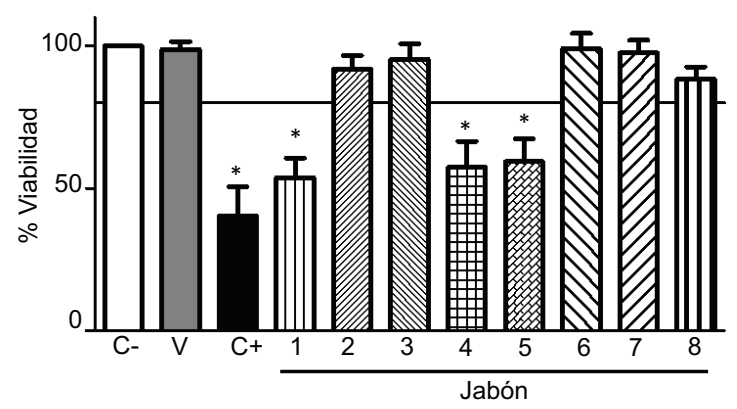

Figura 1. Efecto citotóxico de los jabones en cultivos de queratinocitos. Porcentaje de viabilidad de los cultivos de queratinocitos expuestos a las soluciones de jabón mediante ensayo de resazurina. Se utilizó el medio de cultivo como control negativo (C-), solución fisiológica como vehículo (V) y $0.3 \%$ de agua como control positivo $(C+)$. La línea negra horizontal indica $80 \%$ de viabilidad, que representa el umbral del efecto citotóxico. Los resultados corresponden a la media $\pm D E$ de cinco cultivos realizados por duplicado. *Diferencia significativa respecto al control negativo ( $p<0.05$, Anova).

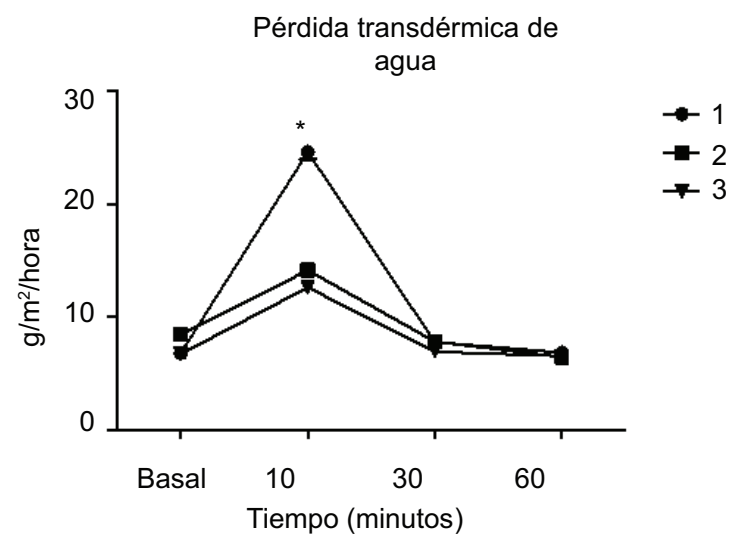

Figura 2. El jabón más citotóxico causó irritación cutánea en sujetos sanos. Niveles de pérdida transepidérmica de agua en piel no fotoexpuesta de sujetos sanos, con la solución de jabón más citotóxico (1) y menos citotóxico (2); mediciones basal y después de 10, 30 y 60 minutos de exposición al jabón. Como control de vehículo (V) se utilizó agua fisiológica salina. Los resultados corresponden a la media $\pm D E$ de 30 sujetos. *Diferencia significativa respecto a los otros grupos ( $p<0.05$, Anova).

50. Se incluyeron 12 hombres y 18 mujeres. El fototipo fue III en siete voluntarios, IV en 14 y $\mathrm{V}$ en nueve.

\section{Citotoxicidad}

La viabilidad de los queratinocitos fue modificada por algunas de las soluciones jabonosas estudiadas, tomando como referencia el control negativo (Anova, $p=0.001$ ). Los jabones 1,4 y 5 disminuyeron la viabilidad de los queratinocitos; en contraste con los jabones 2, 3, 6, 7 y 8 que no los modificaron (Figura 1).

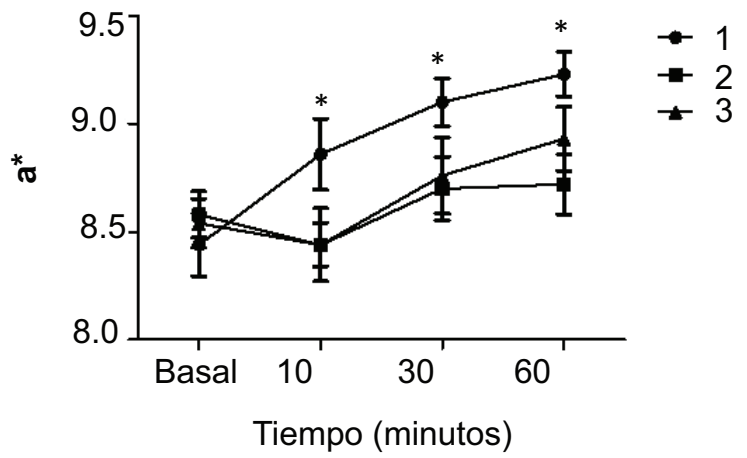

Figura 3. Eritema cuantificado mediante el valor de $a^{*}$ del espacio de color CIELAB en piel no fotoexpuesta de sujetos sanos. Se muestran las curvas para las soluciones con jabón más y menos citotóxicas ( 1 y 2, respectivamente), de forma basal y después de 10, 30 y 60 minutos de exposición. Como control de vehículo (V) se utilizó agua fisiológica salina. Los resultados corresponden a la media $\pm D E$ de 30 voluntarios. *Diferencia significativa respecto a los otros grupos $(p<0.05$, Anova).

\section{Irritación cutánea}

- Pérdida transepidérmica de agua. En relación con los resultados del ensayo de citotoxicidad, las soluciones 1 y 2 se evaluaron in vivo por su menor y mayor viabilidad celular in vitro, respectivamente. A los 10 minutos de su aplicación, ambos jabones mostraron incremento en la pérdida transepidérmica de agua (Anova, $p=0.01$ ); sin embargo, la solución 1 mostró mayor evaporación respecto a la solución 2 y el vehículo. Después de 60 minutos, la piel expuesta a las tres soluciones regresó a sus valores basales, como se observa en la Figura 2.

- Colorimetría. El eritema se cuantificó mediante el valor del eje $\mathrm{a}^{*}$ del espacio de color CIELAB. La solución jabonosa 1 incrementó los valores basales de $8.4 \pm 0.7$ a $8.8 \pm 0.7,9.1 \pm 0.5$ y $9.2 \pm 0.4$ a los 10,30 y 60 minutos, respectivamente (Anova, $p=0.01$ ). La solución 2 y el vehículo no mostraron cambios significativos (Figura 3).

\section{Discusión}

La utilización del jabón es fundamental en el aseo de la población mexicana. Se ha demostrado que el uso excesivo o continuo de este producto genera estrés, irritación e inflamación en la piel, que en la práctica clínica se tipifica como dermatitis de contacto. $^{10}$ Los efectos del jabón sobre la piel se han relacionado con su capacidad para modificar el $\mathrm{pH}$ 
del estrato córneo, ${ }^{11}$ así como con el efecto tóxico de sus ingredientes sobre las células epidérmicas. ${ }^{7} \mathrm{El}$ jabón es considerado un producto cosmético y en México es regulado por la Comisión Federal para la Protección contra Riesgos Sanitarios (Cofepris), y la Procuraduría Federal del consumidor (Profeco). El marco legal para su comercialización lo establece la Norma Oficial Mexicana NOM-039-SSA1-1993, Bienes y Servicios. Productos de Perfumería y Belleza. Determinación de los Índices de Irritación Ocular, Primaria Dérmica y Sensibilización, así como la NOM141-SSA1-1995, Bienes y Servicios. Etiquetado para Productos de Perfumería y Belleza Preenvasados. Dado que no son productos sujetos a farmacovigilancia, se desconocía el efecto nocivo de estos compuestos químicos sobre la piel de la población mexicana.

Los ensayos de citotoxicidad demostraron que $37 \%$ de los jabones analizados redujeron la viabilidad de los queratinocitos, después de la exposición en condiciones equiparables a la de un lavado de manos o ducha corporal habitual. Por lo tanto, podría especularse que la exposición prolongada y una concentración mayor serían capaces de generar mayor toxicidad..$^{9}$ En este trabajo, el pH no mostró relación con el efecto tóxico de los jabones, a diferencia de lo hallado en otras investigaciones que lo asocian a la capacidad de generar irritación clínica de forma directa. ${ }^{4,11}$ Respecto a la inducción de toxicidad, desconocemos qué sustancia o sustancias químicas de los productos son las responsables; sin embargo, el efecto nocivo podría estar relacionado con los surfactantes que emplean. ${ }^{7}$ Esta hipótesis se sustenta en que diversos ingredientes de los productos que produjeron citotoxicidad también estaban incluidos en los que no la presentaron (por ejemplo, conservadores, colorantes, humectantes) y solo encontramos variaciones en el tipo de surfactante. En nuestra muestra, los productos con mayor toxicidad incorporaron surfactantes aniónicos, los cuales se han descrito como más agresivos para la superficie cutánea. ${ }^{12}$ Los menos tóxicos combinaron surfactantes aniónicos y anfotéricos, lo cual pudo condicionar la mayor viabilidad celular. $^{2}$

A diferencia de los jabones menos tóxicos, el jabón de mayor citotoxicidad generó mayor irritación, evaluada mediante la pérdida de agua y el eritema cutáneo. En esta investigación, la piel fue expuesta al dermolimpiador durante un periodo similar al del lavado cotidiano de manos en México, breve en relación con el analizado en otros estudios. ${ }^{6}$ Durante ese intervalo, el jabón fue capaz de disolver lípidos del estrato córneo, penetrar y afectar los queratinocitos de la epidermis, lo cual confirma los hallazgos de otros análisis en los que la limpieza cutánea en un evento único induce la deshidratación del estrato córneo. ${ }^{13,14}$ La normalización de los parámetros biofísicos fue detectada hasta 60 minutos después de la exposición. Este hallazgo es importante, ya que en pacientes con mayor predisposición a sufrir dermatosis con alteraciones en la barrera cutánea como dermatitis atópica, xerosis o ictiosis, el periodo de recuperación podría ser más prolongado. ${ }^{15}$

Conforme a nuestros hallazgos, la limpieza repetida con jabón antes de que se restablezca la función de barrera de la piel pudiera favorecer la disfunción crónica cutánea en la población mexicana. ${ }^{9,16}$ Aunque la demostración de lo anterior no fue el objetivo de este estudio, el uso frecuente del jabón podría contribuir a la aparición continúa o intermitente de dermatitis de contacto irritativa, así como a cambios tisulares que se expresan clínicamente como envejecimiento cutáneo, debido a que el efecto tóxico sobre las células aumenta el estrés oxidativo dañando el ADN y disminuye los mecanismos de reparación de las células condicionando su muerte prematura. ${ }^{17-19}$

Algunas limitaciones de este trabajo consisten en que solo se analizaron los jabones en barra y no presentaciones en gel, espuma o líquido. Tampoco se incluyó la totalidad de los productos en el mercado, sino los de mayor consumo referidos por una muestra poblacional. Por otra parte, será interesante conocer si existe diferencia entre presentación, precio y cantidad de estos productos en relación con su efecto tóxico; así como su efecto nocivo en pacientes con enfermedades cutáneas específicas, como dermatitis atópica.

\section{Conclusión}

Nuestro estudio evidencia la relación entre la actividad tóxica de algunos jabones para uso comercial en México determinada in vitro y las alteraciones subclínicas que originan in vivo, detectadas después de un periodo de contacto relativamente breve y cuantificadas por métodos biofísicos; el restablecimiento de la barrera de la piel se observó hasta una hora después.

Advertimos que, según su frecuencia y la cantidad de producto empleado, el uso de jabón para la limpieza de la piel podría tener implicaciones sobre la salud cutánea, al favorecer la aparición, exacerbación o persistencia de dermatosis inflamatorias, así como inducir procesos degenerativos agudos o crónicos. 


\section{Agradecimientos}

Agradecemos al doctor Iván Nelinho Pérez Maldonado, del Laboratorio de Toxicología Molecular de la Coordinación para la Innovación y Aplicación de la Ciencia y la Tecnología (Laboratorio Nacional, Conacyt), por facilitar la infraestructura necesaria para el desarrollo de este proyecto.

\section{Conflicto de intereses}

Los autores declaran que no existe conflicto de interés

\section{Financiamiento}

Este estudio fue financiado con recursos del Departamento de Dermatología del Hospital Central "Dr. Ignacio Morones Prieto" en San Luis Potosí, México.

\section{Responsabilidades éticas}

Protección de personas y animales. Los autores declaran que los procedimientos se llevaron a cabo de conformidad con las normas éticas del comité de experimentación humana responsable y de acuerdo con la Asociación Médica Mundial y la Declaración de Helsinki.

Confidencialidad de los datos. Los autores declaran que siguieron los protocolos de su centro de trabajo sobre la publicación de datos de pacientes.

Derecho a la privacidad y consentimiento informado. Los autores declaran que en este artículo no aparecen datos de los voluntarios participantes.

\section{Bibliografía}

1. Shahinuzzaman M, Yaakob Z, Moniruzzaman M. Medicinal and cosmetics soap production from Jatropha oil. J Cosmet Dermatol. 2016;15:185-193.
2. Yokoi A, Endo K, Ozawa T, Miyaki M, Matsuo K, Nozawa K, et al. A cleanser based on sodium laureth carboxylate and alkyl carboxylates washes facial sebum well but does not induce dry skin. J Cosmet Dermatol. 2014;13:245-252.

3. Hovi T, Ollgren J, Savolainen-Kopra C. Intensified hand-hygiene campaign including soap-and-water wash may prevent acute infections in office workers, as shown by a recognized-exposure -adjusted analysis of a randomized trial. BMC Infect Dis. 2017;17:1-9.

4. Baranda L, González-Amaro R, Torres-Álvarez B, Álvarez C, Ramírez V. Correlation between $\mathrm{pH}$ and irritant effect of cleansers marketed for dry skin. Int J Dermatol. 2002;41:494-499.

5. Han H, Roan F, Ziegler SF. The atopic march: current insights into skin barrier dysfunction and epithelial cell-derived cytokines. Immunol Rev. 2017;78:116-130.

6. Khosrowpour Z, Nasrollahi SA, Ayatollahi A, Samadi A, Firooz A. Effects of four soaps on skin trans-epidermal water loss and erythema index. J Cosmet Dermatol. 2018;18:857-861.

7. Korting HC, Herzingera T, Hartingerb A, Kerschera M, Angerpointner T, Maibachd HI. Discrimination of the irritancy potential of surfactants in vitro by two cytotoxicity assays using normal human keratinocytes, $\mathrm{Ha}$ CaT cells and 3 T3 mouse fibroblasts: Correlation with in vivo data from a soap chamber assay. J Dermatol Sci. 1994;7:119-129.

8. CSA [Internet]. ISO 10993-5:2009. Biological evaluation of medical devices -Part 5: Tests for in vitro cytotoxicity; 2009.

9. Williams C, Wilkinson M, McShane P, Pennington D, Fernandez C, Pierce $\mathrm{S}$. The use of a measure of acute irritation to predict the outcome of repeated usage of hand soap products. Br J Dermatol. 2011;164:1311-1315.

10. Warren R, Ertel KD, Bartolo RG, Levine MJ, Bryant PB, Wong LF. The influence of hard water (calcium) and surfactants on irritant contact dermatitis. Contact Dermatitis. 1996;35:337-343.

11. Gonçalves GM, Brianezi G, Miot HA. The $\mathrm{pH}$ of the main Brazilian commercial moisturizers and liquid soaps: considerations on the repair of the skin barrier. An Bras Dermatol. 2017;92:376-378.

12. Draelos Z, Hornby S, Walters RM, Appa Y. Hydrophobically modified polymers can minimize skin irritation potential caused by surfactant-based cleansers. J Cosmet Dermatol. 2013;12:314-321.

13. Moore PN, Shiloach A, Puvvada S, Blankschtein D. Penetration of mixed micelles into the epidermis: effect of mixing sodium dodecyl sulfate with dodecyl hexa (ethylene oxide). J Cosmet Sci. 2003;54:143-159.

14. Bornkessel A, Flach M, Arens-Corell M, Elsner P, Fluhr JW. Functional assessment of a washing emulsion for sensitive skin: Mild impairment of stratum corneum hydration, $\mathrm{pH}$, barrier function, lipid content, integrity and cohesion in a controlled washing test. Skin Res Technol. 2005;11: 53-60.

15. Del Rosso JQ, Levin J. The clinical relevance of maintaining the functional integrity of the stratum corneum in both healthy and disease-affected skin. J Clin Aesthet Dermatol. 2011;4:22-42.

16. Grunewald AM, Gloor M, Gehring W, Kleesz P. Damage to the skin by repetitive washing. Contact Dermatitis. 1995;32:225-232.

17. Zijno A, De Angelis I, De Berardis B, Andreoli C, Russo MT, Pietraforte D, et al. Different mechanisms are involved in oxidative DNA damage and genotoxicity induction by $\mathrm{ZnO}$ and $\mathrm{TiO} 2$ nanoparticles in human colon carcinoma cells. Toxicol In Vitro. 2015;29:1503-1512.

18. Tyagi N, Srivastava SK, Arora S, Omar Y, ljaz ZM, Al-Ghadhban A, et al. Comparative analysis of the relative potential of silver, zinc-oxide and titanium-dioxide nanoparticles against UVB-induced DNA damage for the prevention of skin carcinogenesis. Cancer Lett. 2016;383:53-61.

19. Du J, Wang S, You H, Jiang R, Zhuang C, Zhang X. Developmental toxicity and DNA damage to zebrafish induced by perfluorooctane sulfonate in the presence of ZnO nanoparticles. Environ Toxicol. 2016;31:360-371. 